\title{
Left circumflex arising from the right coronary artery and silent myocardial ischaemic damage: a potentially lethal disarray detected by cardiac $\mathrm{CT}$ and SPECT
}

\author{
Gian Piero Carboni, ${ }^{1}$ Pietro Sedati ${ }^{2}$
}

${ }^{1}$ Department of Nuclear Cardiology, Università Campus Bio-Medico, Rome, Italy ${ }^{2}$ Department of Radiology, Università Campus Bio-Medico, Rome, Italy

\section{Correspondence to} Dr Gian Piero Carboni; g.carboni@unicampus.it

\section{DESCRIPTION}

In 2012 December, a 68-year-old man presented with mild effort dyspnoea, paroxysmal atrial fibrillation and type 2 diabetes. The ECG was within normal limits. Echocardiography documented septal and inferior left ventricle (LV) hypokinesia. Stress/rest technetium-99m sestamibi (MIBI)-gated, singlephoton emission, cardiac tomography revealed septal and inferior wall defects with mild reversibility (figure 1) and reduced contractility. The submaximal exercise test was negative. ${ }^{1}{ }^{2}$ Cardiac tomography documented an anomalous origin in the left circumflex artery (AOLCX) arising from the right coronary artery and coursing between the aorta and the left atrium (figures 2-4). Direct angiography excluded the presence of atherosclerotic disease. The systolic compression of the AOLCX produced by the aorta and left atrium during daily activities resulted in a transient reduction in coronary flow. The LV regional contractile anomalies were most likely a consequence of fibrotic myocardial damage due to brief but repetitive episodes of myocardial ischaemia. ${ }^{3}$ The absence

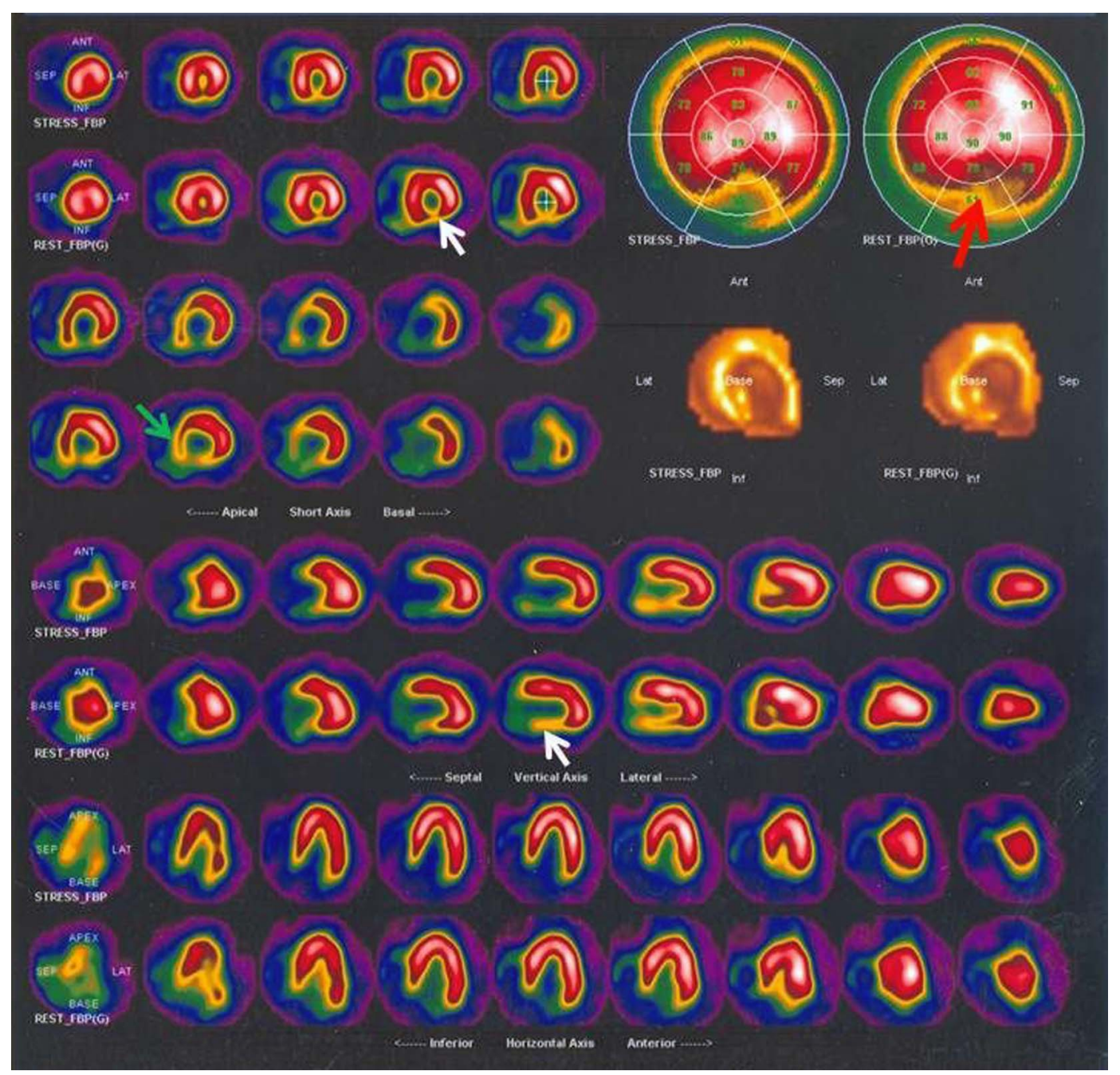

Figure 1 Stress/rest technetium-99m sestamibi (MIBI) single-photon emission cardiac tomography. Inferior (white arrows) and septal (green arrow) perfusion defects with mild reversibility. Polar maps better document the mild reversibility of the defects (red arrow). 


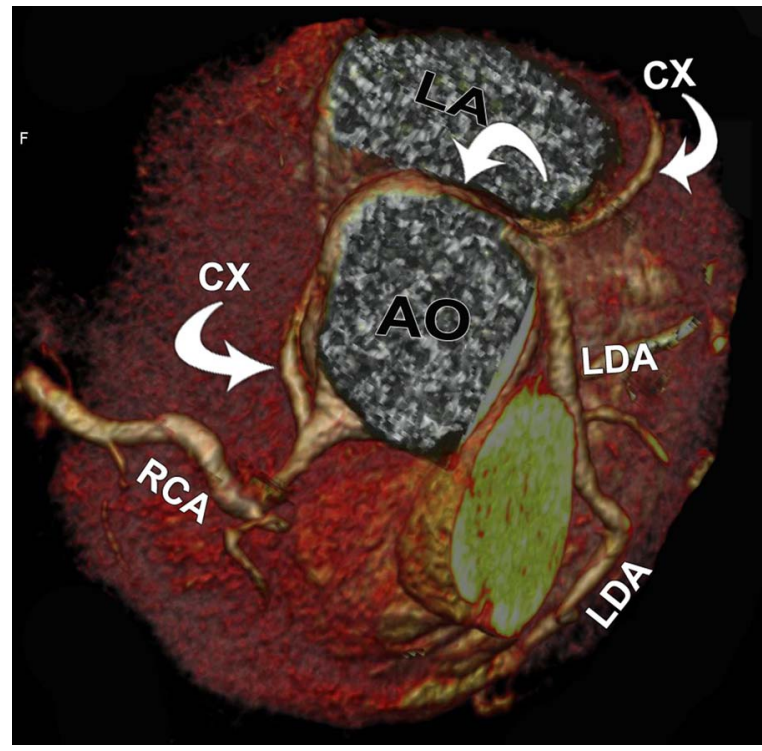

Figure 2 Spider view three-dimensional volume-rendered CT images indicate an anomalous origin of the left circumflex coronary artery (CX) arising from the right coronary artery (RCA) and coursing between the aorta (AO) and the left atrium (LA). LDA, left anterior descending coronary artery; RCA, right coronary artery.

of angina was likely due to the neuropathy caused by diabetes. ${ }^{4}$ The risk of sudden death (SD) has been reported in patients with AOLCX. ${ }^{5}$ However, an ectopic left coronary artery is more likely to cause SD due to the greater ischaemic territory involved. ${ }^{6}$ Moreover, this risk decreases with age. In this patient, the combination of fibrosis, ischaemia and normal tissue may imply electrical instability and life-threatening arrhythmias due to enhanced automaticity, triggered activity or re-entry. ${ }^{7}$ As the ischaemia was mild, surgery was not indicated and the $\beta$-blocker dose was increased to provide greater myocardial protection.

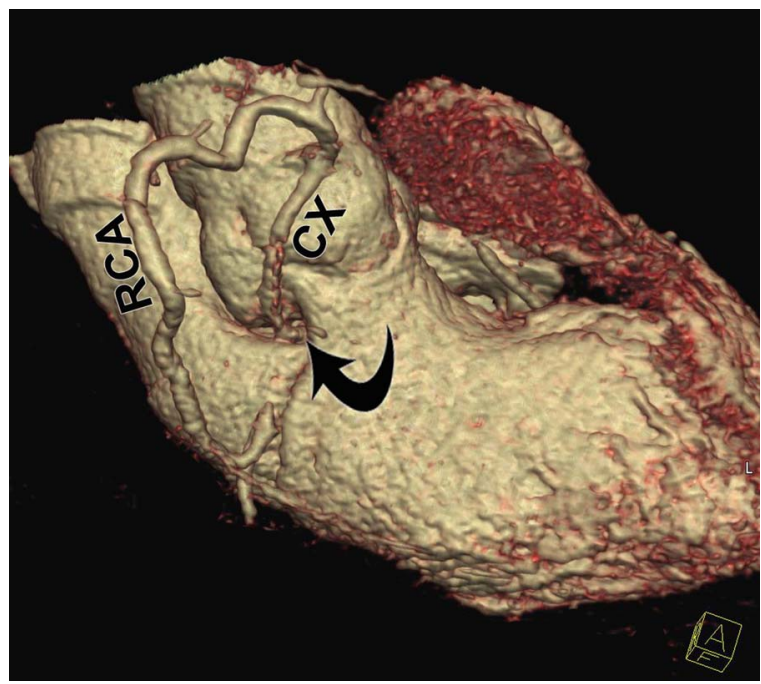

Figure 3 Right oblique three-dimensional volume-rendered CT image demonstrates the anomalous origin of the left circumflex artery (CX) from the right coronary artery (RCA) and its course in the groove between left ventricular outflow tract and anterior wall of the left atrium (arrow).

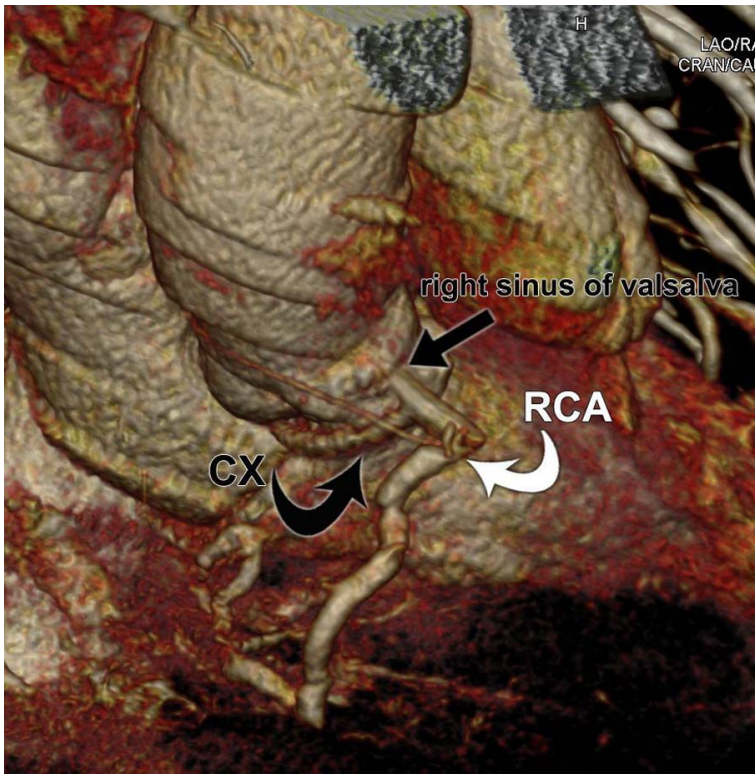

Figure 4 Right oblique superior three-dimensional volume-rendered CT image demonstrates the anomalous origin of the left circumflex coronary artery (curved black arrow) from the right coronary artery (curved white arrow). There is $3 \mathrm{~mm}$ long common trunk arising from the right sinus of Valsalva (small arrow) that bifurcates into the left circumflex and right coronary arteries. CX, coronary artery; RCA, right coronary artery.

\section{Learning points}

- A negative submaximal exercise test is a frequent finding in patients with congenital coronary anomalies.

- In the temporal sequence of the pathophysiological cardiac changes that culminate in ischaemia, abnormal myocardial perfusion on single-photon emission cardiac tomography (SPECT) imaging precedes ST-segment depressions on an exercise test. Compared to an exercise test, SPECT imaging has greater diagnostic capacity for identifying myocardial ischaemia.

- Cardiac CT has been established as an excellent non-invasive test to identify and classify congenital coronary artery anomalies.

Contributors GPC was involved in writing the manuscript. PS performed the CT imaging and was involved in revision of the manuscript. Both the authors approved the final version of manuscript to be published.

\section{Competing interests None.}

Patient consent Obtained.

Provenance and peer review Not commissioned; externally peer reviewed.

\section{REFERENCES}

1 Edwards CP, Yavari A, Sheppard MN, et al. Anomalous coronary origin: the challenge in preventing exercise-related sudden cardiac death. $\mathrm{Br}$ J Sports Med 2010;44:895-7.

2 Nesto RW, Kowalchuk GJ. The ischemic cascade: temporal sequence of hemodynamic, electrocardiographic and symptomatic expressions of ischemia. Am J Cardiol 1987:59:23C-30C 
3 Frangogiannis NG, Dewald O, Xia Y, et al. Critical role of monocyte chemoattractant protein-1/CC chemokine ligand 2 in the pathogenesis of ischemic cardiomyopathy. Circulation 2007:115:584-92.

4 Nesto RW, Phillips RT, Kett KG, et al. Angina and exertional myocardial ischemia in diabetic and nondiabetic patients: assessment by exercise thallium scintigraphy. Ann Intern Med 1988;108:170-5.
5 Corrado D, Penelli T, Piovesana P, et al. Anomalous origin of the left circumflex coronary arten from the right aortic sinus of Valsalva and sudden death. Cardiovasc Pathol 1994;3:269-71.

6 Taylor AJ, Rogan KM, Virmani R. Sudden cardiac death associated with isolated congenital coronary artery anomalies. J Am Coll Cardiol 1992;20:640-7.

7 Gaztañaga L, Marchlinski FE, Betensky BP. Mechanisms of cardiac arrhythmias. Rev Esp Cardiol (Engl Ed) 2012;65:174-85.

Copyright 2013 BMJ Publishing Group. All rights reserved. For permission to reuse any of this content visit http://group.bmj.com/group/rights-licensing/permissions.

BMJ Case Report Fellows may re-use this article for personal use and teaching without any further permission.

Become a Fellow of BMJ Case Reports today and you can:

- Submit as many cases as you like

- Enjoy fast sympathetic peer review and rapid publication of accepted articles

- Access all the published articles

- Re-use any of the published material for personal use and teaching without further permission

For information on Institutional Fellowships contact consortiasales@bmigroup.com

Visit casereports.bmj.com for more articles like this and to become a Fellow 